\title{
Structural Change in the Crude Oil Price Dynamic: Theoretical Study and Practical Implications
}

\author{
Francisco Gironés \\ Colegio Universitario de Estudios Financieros (CUNEF), C/ Serrano Anguita, 9, 28004 \\ Madrid, Spain \\ Tel: +34914480892Ｅ-mail: Francisco.Girones@ cunef.edu \\ Fernando Guerra \\ Colegio Universitario de Estudios Financieros (CUNEF), C/ Serrano Anguita, 9, 28004 \\ Madrid, Spain \\ Tel: +34914480892Ｅ-mail: Fernando.Guerra@cunef.edu \\ Jorge Hernández \\ Colegio Universitario de Estudios Financieros (CUNEF), C/ Serrano Anguita, 9, 28004 \\ Madrid, Spain \\ Tel: +34914480892Ｅ-mail: Jorge.Hernandez@cunef.edu
}

\author{
Javier Población (Corresponding author) \\ D.G.A. Supervisión, Banco de España, C/ Alcalá 48, 28014, Madrid, Spain
}

Tel: +34913385812Ｅ-mail: javier.poblacion@bde.es

Received: November 12, 2012 Accepted: November 26, 2012

doi:10.5296/ber.v3i1.2673 URL: http://dx.doi.org/10.5296/ber.v3i1.2673

\begin{abstract}
As many researchers know, the price of oil was affected by a structural change, which we analyzed. We obtained the result of the Chow test (determining the date when the structural break occurred). We observed that important data such as the variance or the VAR vary
\end{abstract}


significantly depending on the period that the data are taken from, with huge implications in the financial world. If an investor wanted to create a portfolio, selecting an inadequate variance and VAR could lead to erroneous results. If an investor creates a portfolio composed of certain assets and assumes a volatility of $20 \%$, and volatility is actually $30 \%$, the actual results could vary materially from those expected. In this study, we observed that the variance is generally higher after the structural change in oil and for oil companies.

Keywords: Structural Change, Commodity Prices, Value-at-Risk, Causality

JEL Codes: C32, C51, C60, G13.

This version: December 2012.

\section{Introduction}

In the last decade, the dynamics of oil prices have undergone important changes. Until 2000, without taking into consideration time points such as the oil crises of the 1970s or the first Iraq war, oil prices were very stable, without significant variation from a given equilibrium level $(18-20 \$ / b b l)$.

However, since 2001, the price of oil has become extremely volatile. From 2001 to 2007, there was a steady increase that multiplied the price by eight over these years (the price of oil reached $150 \$ / \mathrm{bbl}$ ), while more recently, oil suffered a severe correction (the price of crude dropped to $35 \$ / \mathrm{bbl}$ ). Currently, the price of crude stays at approximately $60-80 \$ / \mathrm{bbl}$, far above the equilibrium level.

The reasons for this deep change in behavior are unclear. It is true that in the first decade of this century, a series of events have occurred that could be considered to be "shocks" to the oil price: 9-11, the second Iraq war, the excessive growth of emerging countries such as China and India, the relative coordination of the cartel (OPEC), tensions in the Middle East, massive financial crises, ... However, none of these more recent events has been of a greater magnitude than the "shocks" that occurred historically: the war in the Middle East, the Iraq war, OPEC, ... However, for no apparent reason, the historic "shocks" were transient whereas those sustained in the last decade have proved to be permanent.

That is why today, from the point of view of a financial investor, oil has shifted from being a "commodity" (a raw material) to being considered a financial asset, more similar to precious metals than to the perishable commodities. In fact, in recent years, the commodities in the derivatives markets have evolved in a spectacular way, and have considerably increased the number of speculators in these markets. Many analysts attribute the structural change in the dynamics of prices to these speculators.

Whatever the reason may be, the reality is that at present, the efficient frontier of investment possibilities for the average investor has increased with these new financial assets: oil, refined products (gasoline, diesel, LGPS, .) and gas, mainly natural gas.

The financial theory of efficient markets begins with the fact that at a single point, all of the 
information available on the market is built into the price, making it impossible to predict future price changes. No investor has a crystal ball to know if the price of these assets will go down or up in the future. What is important to note is that the forward prices use all of the information available today about the evolution of the price. Future deviations of these prices do not mean anything except that new information has entered the market and affected the expectations of investors. For this reason, it is not important if good or bad news occurs; what matters is whether the new information is better or worse than current expectations of the investors.

In any case, what we can understand are the advantages to an investor of investing in these assets. These benefits derive from the fact that the correlation of these assets with the market portfolio is not as high as the correlation between any two assets in that market portfolio. That is, investing in these new assets has the potential for greater risk diversification, which is always positive for investors. Another advantage of these investments comes from the fact that they are physical assets, which, like raw materials, can be considered to be a value refuge during times of financial turbulence.

However, the investments in these assets are not risk free, and this is important to highlight. With the new dynamics of prices, these assets are highly volatile, which carries greater risk. Additionally there is the problem of storage. If you invest in a derivative of these hydrocarbons, there is no choice but to settle for differences due to the high cost of storage.

In recent times, both academics and practitioners have focused on the valuation and hedging of commodity contingent claims and the procedures for evaluating natural resource investment projects. In particular, they are concerned with finding a rule to determine when it is optimal to invest. The stochastic behavior of commodity prices plays a central role in answering this question. The first work on the stochastic behavior of commodity prices relied on the assumption that spot prices follow a geometric Brownian motion (for example, see Brennan and Schwartz, 1985, and Paddock et al., 1988, among others). However, the geometric Brownian motion hypothesis implies a constant rate of growth in the commodity price and a constant volatility of the futures price returns, which are not realistic assumptions. In practice, commodity prices exhibit mean reversion and the volatility of futures returns is a decreasing function of time.

Consequently, several authors, such as Laughton and Jacobi (1993) and (1995), Ross (1997) and Schwartz (1997) have considered whether the stochastic behavior of commodity prices might be better described by a mean-reverting process. Unfortunately, one-factor mean-reverting models are not very realistic. These models generate the volatility of futures returns, which moves to zero as the time to maturity of the futures contract approaches infinity. Moreover, the models that consider a single source of uncertainty are not very realistic. These models imply that the futures prices for different maturities should be perfectly correlated, defying the existing evidence. In an attempt to produce more realistic results, researchers have turned to multi-factor models (Schwartz, 1997; Schwartz and Smith, 2000; Cortazar and Schwartz, 2003; Cortazar and Naranjo, 2006). These multi-factor models assume that the spot price is the sum of short- and long-term components. The long-term factors account for the 
long-term dynamics of commodity prices, which is assumed to be a random walk, whereas the short-term factors account for the mean reverting components in commodity prices.

The petroleum industry occupies an unusually prominent place in the US economy. Unlike most other products, consumers are acutely aware of variations in the price of gasoline and home heating oil. Not only do changes in the prices of these commodities affect consumers directly, the supply conditions for petroleum products also influence many sectors of the economy. Perhaps no other industry's performance is so visibly and deeply felt (The Petroleum Industry; Federal Trade Commission 2004).

In this paper, we will start with a small review of the risks that can affect this industry before proceeding into an in-depth study about any possible structural change in the price of oil and other related financial assets. We will also analyze the Value at Risk (VAR) of each of the assets that we feel it could be interest to study.

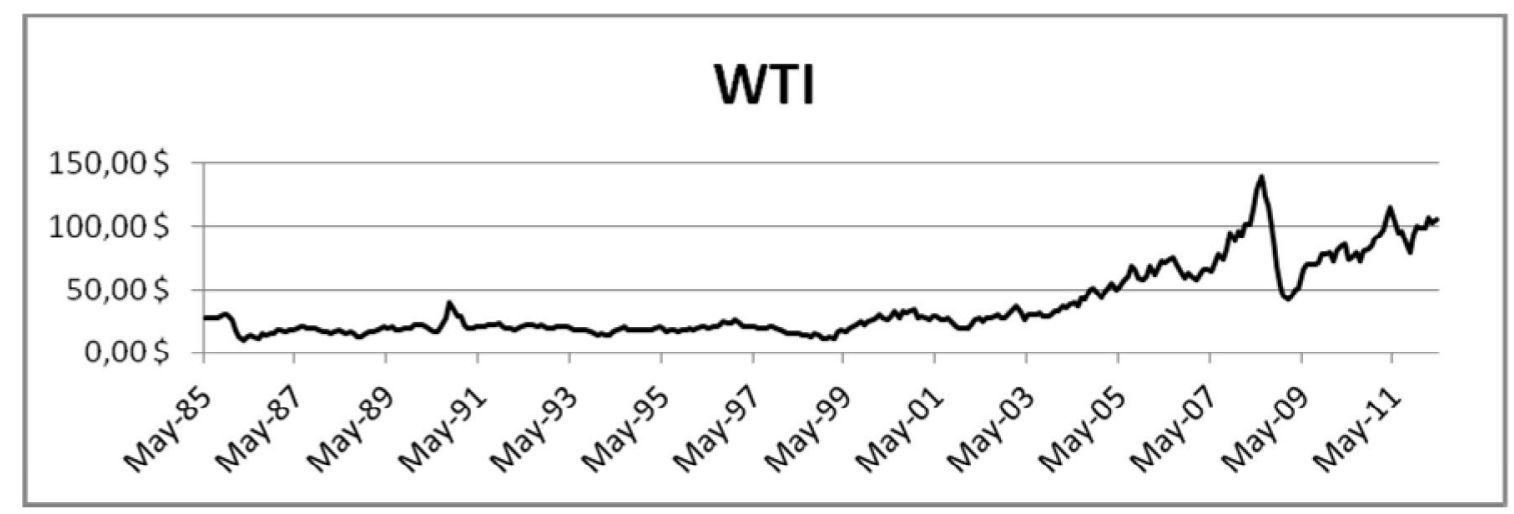

Figure 1. (Oil prices May. 1985 : May. 2011)

In this Figure, we can easily see that oil prices remained stable from 1985 to 2001, although we can observe a peak in 1991 because of the Iraq war. Since 2001, the performance of the prices changed and increased sharply. Prices leveled out in 2002 under pressure from stronger domestic oil demand, low crude oil inventories, and, at the end of the year, labor strikes that resulted in the near cessation of oil exports from Venezuela. Domestic prices climbed above $\$ 28$ per barrel in January 2003, reached almost \$32 in February preceding the war in Iraq, and then fell to $\$ 25$ per barrel by September 2003.

From September 2003 through April 2004, domestic crude oil prices increased by roughly one dollar per barrel each month to reach $\$ 33.21$ in April 2004. On July 12, 2004, WTI, a light, sweet crude oil, traded at $\$ 39.50$ per barrel. Examining all of these facts and some others, we can suppose that a structural change in oil prices could have been influencing these changes.

An important factor to realize in this paper is that there are many types of risks that can affect the oil industry. These risks affect the price of oil, but the majority of these risks have always been there and may be closely related to the volatility in the price of oil. These risks are not the reason that there has been a structural change in the price of oil. The reason for this structural change is more closely related to the strong growth in some emerging countries that are importers of gasoline such as China and India that, among other reasons that we will explain 


\section{Macrothink}

during this paper, has made the demand rise exponentially.

These facts are permanent and not casual, which has created some uncertainty for consumers. This uncertainty has resulted in an increasing number of speculators who come to the derivatives market to protect themselves from potential price increases, such as in the case of airlines and similar companies that can be significantly affected by a change in the price of gasoline. In turn, other investors are attracted to the market who seeks to profit by speculating on the possible ups and downs in the price of gasoline.

The goal of this research is primarily to attempt to discover if there was a change in the structure of oil prices and oil companies and, if there was, when this change occurred. Moreover, this paper attempts to identify what implications this change has had for the statistical properties of the asset prices. The study of the dynamics of oil prices is justified by its role in the regional and global economies. There has been much research performed to improve the understanding of the dynamics of oil prices since the crisis of the seventies and to analyze the impact of changes in oil prices on macroeconomic activities. The movement of oil prices is complex; it is characterized by rises, falls, and trends that hinder the understanding of its dynamics, and it can be explained by different economic theories.

This paper is organized as follows. In section 2, the data are presented. The Chow test is developed in Section 3. Section 4 contains a causality analysis, and section 5 applies the structural change to the risk measurement through a VaR analysis.

\section{Data}

In this section, we will present the data that we will use in this study. We will use data from commodities, stock price companies and indices as included in table 1.

Table 1.

\begin{tabular}{|c|c|}
\hline Commodity & Data \\
\hline •WTI & • Jun. 1985 : Jun. 2007 \\
\hline - Brent & - Sep. 1988 : Jun. 2007 \\
\hline - Diesel & - Sep. 1988 : Jun. 2007 \\
\hline Companies & Data \\
\hline - Repsol & - Dec. 1995 : Dec. 2007 \\
\hline - Enersis & - Dec. 1995 : Dec. 2007 \\
\hline - British Petroleum & - Sep. 1988 : Jun. 2007 \\
\hline - Shell & - Sep. 1988 : Jun. 2007 \\
\hline - Chevron & - Jun. 1985 : Jun. 2007 \\
\hline Index & Data \\
\hline - Index Production & - Jun. 1985 : Jun. 2007 \\
\hline - Consumer Price Index & - Jun. 1985 : Jun. 2007 \\
\hline • MSCI & - Jun. 1985 : Jun. 2007 \\
\hline
\end{tabular}


As shown in the table, there are series of different types of commodities such as West Texas Intermediate crude oil or Diesel. Apart from these data, we chose the most relevant oil companies so that we could present an important and diversified range of companies.

However, the data series presented some problems; some of the data series were not long enough, and therefore we had to create many scenarios. To complete this paper, we obtained a monthly data series (we considered that a yearly series would be present enough data to obtain an accurate result) of the prices and values of the following commodities, companies and indexes:

To determine whether there is a structural change, we will conduct a linear regression. We have assumed that there is relationship between the prices of the assets and some index, so we selected the following indexes, which we considered to be appropriate for our study:

Consumer Price Index, which "measures changes in the price level of consumer goods and services purchased by households" for the USA (calculated and issued on a monthly basis). There is a strong correlation between the oil prices and CPI.

MSCI World, which "is a stock market index of over 16,000 world stocks". There is a strong correlation between the oil prices and MSCI World as well.

Industrial Production Index, which "measures the real production output of manufacturing, mining, and utilities" of the USA. The more items that manufacturers produce, the greater the use of energy resources and therefore the greater demand for oil.

\section{Structural Change}

To discuss the structural change, it is quite important to obtain the variance. If we start from the $\mathrm{T}$ period instead of the $\mathrm{T}+1$ period, we would most likely obtain different results and, what is more, if there was a structural break, this difference would be greater. Sometimes when the data series for commodities and oil companies suffer from a structural break, it involves a change in their behavioral trend.

To test whether these data series contain a structural break, we first considered what the linear regression model of a commodity would look like. The price of a commodity depends on many factors, but to simplify this postulation, as we explained previously, the prices of commodities and oil companies are going to depend on some index.

$$
\mathrm{WTI}=\alpha_{0}+\beta_{1} \mathrm{CPI}+\beta_{2} \mathrm{MSCI}+\beta_{3} \mathrm{IPI}
$$

(An example of a linear regression model for the WTI oil type)

\subsection{The Chow Test for Structural Stability}

The fundamental economic analysis shows that the complexity of the evolution of oil can be explained by the dynamic and changing relationships between the producing countries, the oil companies, the refineries, and economic, social, and political events.

As we said above, some data series contain a structural break due to a change in policy or a sudden shock to the economy, i.e., 1973, when the oil price persistence and volatility both 


\section{Macrothink}

Business and Economic Research ISSN 2162-4860 2013, Vol. 3, No. 1

increased. In 1970, U.S.A oil production reached its peak. To test for a structural break, we often use the Chow test. The model uses an F-test to determine whether a single regression is more efficient than two separate regressions, which would involve splitting the data into two sub-samples. (To learn about the Chow test in more detail, read: Dougherty, Christopher (2007) Introduction to Econometrics)

In the first case, we have just a single regression line to fit the data points. This regression can be expressed as follows:

$$
\mathrm{WTI}=\alpha_{0}+\beta_{1} \mathrm{CPI}_{1986-2007}+\beta_{2} \mathrm{MSCI}_{1986-2007}+\beta_{3} \mathrm{IPI}_{1986-2007}
$$

In the second case, where there is a structural break, we have two separate models, expressed as follows:

$$
\begin{aligned}
& \mathrm{WTI}=\alpha_{0}+\beta_{1} \mathrm{CPI}_{1986-2002}+\beta_{2} \mathrm{MSCI}_{1986-2002}+\beta_{3} \mathrm{IPI}_{1986-2002} \\
& \mathrm{WTI}=\alpha_{0}+\beta_{1} \mathrm{CPI}_{2002-2007}+\beta_{2} \mathrm{MSCI}_{2002-2007}+\beta_{3} \mathrm{IPI}_{2002-2007}
\end{aligned}
$$

Following the theory about structural breaks, the expression of the Chow test is simply calculated from the residual quadratic sums:

$$
\begin{gathered}
\mathrm{F}_{\text {-Statistic }}=\left[\left(\text { Sum squared resid }_{85-07}\right)-\left(\text { Sum squared resid }_{85}+\text { Sum squared resid }_{86-07}\right) / k\right] / \\
{\left[\left(\text { Sum squared resid }_{85}+\text { Sum squared resid }_{86-07}\right) /\left(\left(n_{1}+n_{2}\right)-(2 * k)\right)\right]} \\
\mathrm{F}_{\text {-Statistic }}=((31807.7-(12.55865-29751.7) / 4) /((12.55865-29751.7) /(265-2 * 4))
\end{gathered}
$$

This sample value of F can now be compared with the value of F (4.74) to test the null hypothesis that there is no structural change at any level of confidence.

\subsection{Results of the Chow Test}

Using the above equation for the years 1986 and 2002, when we expect there was a structural break, we obtain the followings results for WTI:

Table 2. (Results of Chow Test for WTI for the years 1986 and 2002)

\begin{tabular}{|l|l|l|l|}
\hline \multicolumn{3}{|l|}{ Chow Breakpoint Test: $1986 \mathrm{M} 01$} & \\
\hline F-statistic & 4.4110 & Probability & 0.00182 \\
\hline Log likelihood ratio & 17.5960 & Probability & 0.00148 \\
\hline Chow Breakpoint Test: $2002 \mathrm{M} 01$ & \\
\hline F-statistic & 199.3684 & Probability & 0.0000 \\
\hline Log likelihood ratio & 374.1061 & Probability & 0.0000 \\
\hline
\end{tabular}

The result referring to the calculation of the Chow test is in bold and is presented as the value of the F statistic and its corresponding probability. Recall that the null hypothesis contrasted with the Chow test is the non-existence of structural change. The contrast (the sample value of F) takes a greater value with a greater evidence of structural change. The probability indicates, as for any contrast, the probability of being wrong if we reject the null hypothesis, that is, if we admit the presence of structural change. The evidence of structural change is higher for the 
cutoff 2002:07 among every set of data.

Once we obtained all of the series data that we needed (every data series mentioned above), we obtained the Chow test values for the first month of every year. Once we reached the year in which the value of the Chow test is at a maximum, we obtained the values of the Chow test for each month around that époque. The maximum value of the F-statistic is reached when the structural change reaches its peak. The results obtained were as follows:

Table 3. (Results obtained)

\begin{tabular}{|l|l|}
\hline CHEVRON & 01 MARCH 2001 \\
BP & 01 MARCH 2001 \\
SHELL & 01 JULY 2001 \\
ASFALTO & 01 APRIL 2002 \\
ENI & 01 APRIL 2002 \\
BRENT & 01 JUNE 2002 \\
WTI & 01 JULY 2002 \\
GASOIL & 01 SEPTEMBER 2002 \\
REPSOL & 01 DECEMBER 2002 \\
\hline
\end{tabular}

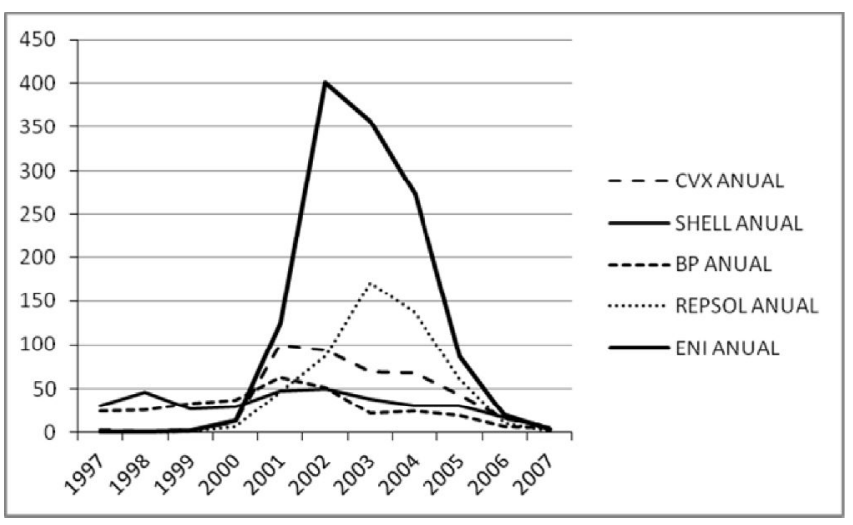

Figure 2. (Figure of the F-statistic of the companies)

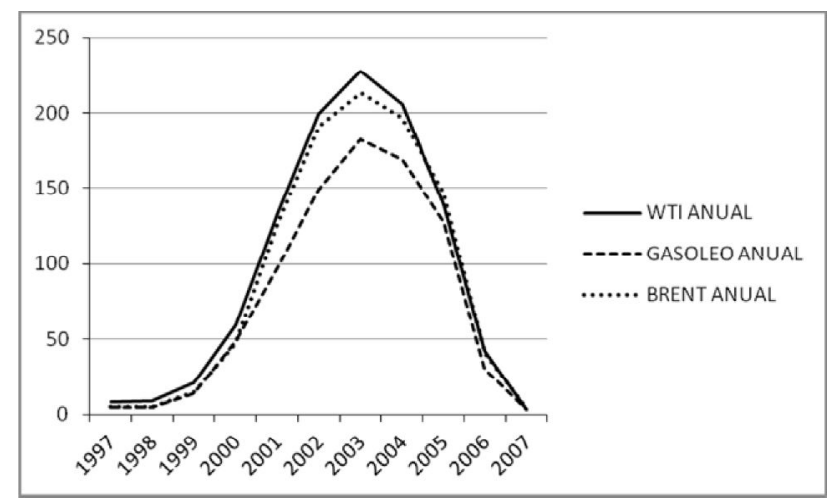

Figure 3. (Figure of the F-statistic of oil and derivatives)

As soon as we have obtained the results of the F-statistic for each date, we can appreciate that since the beginning of the data series, each and every F-statistic is bigger than the unit. This 
result indicates that there is a deep structural change in the prices, but it does not note when this change occurred. We therefore must find when the F-statistic is at its maximum, and we will then know when the structural change was at its maximum. These data are affected by more than one set of events, in 1991 there was another small structural change due to the war in Iraq where the oil prices saw great variations.

It is worth noting that the share prices of the oil companies suffered a structural change before the prices of the Brent or WTI suffered a change.

Now we can assume that there were structural changes in oil prices. First, it was the oil companies that experienced a structural change in their prices, beginning with Chevron. More recently, WTI, GASOIL and Repsol experienced this structural change.

It is remarkable to know that the price relationship among the different types of crude is often highly correlated. If the prices of different crudes move closely together, it may indicate that when the price of one type of crude oil moves far out of line from the other crude prices, it causes the refiners to substitute among crudes.

\section{Granger Causality Test}

To complement the research, we have added another point. Although the share prices of the oil companies experienced the structural change before the oil prices, this does not mean that the evolution of oil prices depends on the evolution of the share prices of the oil companies. We have also analyzed the relationship between the variation in oil prices and the variation in share prices of the oil companies using the Granger Causality test. The Granger causality test is a means of identifying directional connectivity within data using a linear regression analysis.

Granger causality is a statistical concept of causality that is based on prediction. According to Granger causality, if a signal $X_{1}$ "Granger-causes" (or "G-causes") a signal $X_{2}$, then the past values of $X_{1}$ should contain information that helps to predict $X_{2}$ above and beyond the information contained in the past values of $X_{2}$ alone. The mathematical formulation of this test is based on the linear regression modeling of stochastic processes (Granger 1969; Seth, A.K. 2007).

Much of the existing work on predicting the price of oil has focused on testing for the existence of a predictive relationship from the macroeconomic aggregates to the price of oil. However, we are going to predict a relationship between oil and the share prices of the oil companies. The existence of predictability in a population is a necessary precondition for out-of-sample forecast ability.

Predictability in the context of linear vector auto regressions may be tested using Granger causality tests. Table 1a investigates the evidence of Granger causality from oil prices to the price of oil companies. All of the results are based on pairwise vector auto regressions. The lag order is fixed at 1,2 and 3. We observed very similar data in each of the Granger tests (for 1, 2 and 3 lags) for some of these relationships, and we include the patterns in the following figure. We consider four alternative nominal oil price series. Using the data obtained, we assume that there is Granger causality between two assets when the probability of the F-statistic is less than 
$5 \%$; sometimes this causality is not reciprocal and is just one way (as in this case). The evaluation period was 01/1996-01/2007.

After obtaining the results for the Granger causality test with one, two and three lags, we drew the conclusion that the prices of WTI and BRENT set the price trend for the oil companies' shares and, what is more, the WTI, BRENT and ENI set the prices of the Gasoil. In summary, we have reasonable evidence of Granger causality from the price of the WTI and Brent oil types to Repsol, Shell, CVX and Gasoil prices, but not vice versa.

Table 4. (Granger Causality between different assets)

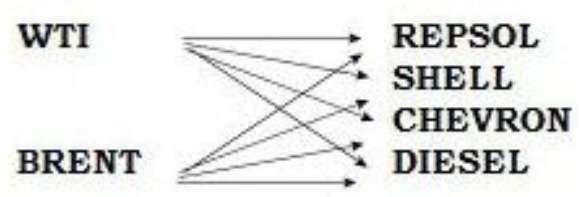

\section{Value at Risk}

When the volatility is higher, the probability for investors of losing or winning money is higher. For this reason, investors ask themselves about the odds of a really large loss, and VAR answers the question "What is my worst-case scenario?" or "How much could an investor lose in a really bad period of time?"

As we know, VAR is defined as a measure of the maximum potential change that the value of our portfolio could suffer during a given time horizon and at a given probability level.

Analyzing the VAR, we must consider three important factors: a time period, a confidence level and a loss percentage.

In all of the cases, we have analyzed the complete series since the structural change of each asset or of the various companies.

With this analysis, we want to show that in almost every case, the VAR is higher since the structural change occurred, followed by the entire sample and finally the two specific periods analyzed (First we analyzed the VAR for each company and oil type in the entire sample, and then we focused on analyzing the two specific periods).

\subsection{Value at Risk: Wti}

The first asset that we analyzed is "WTI" (West Texas intermediate oil); the variables that we found from the prices were the mean $(\mu)$, the standard deviation $(\sigma)$ and p1t-1, which is a specific price at a particular point in the year in our case $(07 / 31 / 2003)$.

\subsubsection{Complete series}

If we analyze all of the prices for all of the years, $\mu=0.62 \%, \sigma=8.87 \%$ and p1t $-1=104.87$.

After making these calculations, we simulate 10,000 random numbers with normal distribution $(0 ; 1)$ (we will call those simulations $\eta)$. We can then obtain 10,000 random simulations of $\varepsilon(\varepsilon=$ 
$\left.\sigma^{*} \eta\right)$.

We then calculate $\mathrm{p} 1 \mathrm{t}$ because $\mu, \varepsilon, \log (\mathrm{p} 1 \mathrm{t}-1): \mathrm{p} 1 \mathrm{t}=\left(\mu+\varepsilon^{+} \log (\mathrm{p} 1 \mathrm{t}-1)\right)$, after: P1t that is $\operatorname{EXP}(p 1 t)$ and that is the possible value with 10,000 random numbers of our portfolio. We must order those numbers from the lowest to the highest.

Sorted once, we find the mean value, 105.9, and the value at 5\%, 91.2. Finally, the VAR at 5\% is the difference between the mean value and the value at $5 \%(105.9-91.2=14.7)$.

If we create a table with various ranges for the values of the portfolio, we will have the following numbers for our observations:

\begin{tabular}{|l|l|}
\hline$\mu$ & $0.62 \%$ \\
\hline$\sigma$ & $8.87 \%$ \\
\hline $\mathrm{p} 1 \mathrm{t}-1$ & 104.87 \\
\hline
\end{tabular}

\begin{tabular}{|l|l|}
\hline Mean value & 105.9 \\
\hline Value at 5\% & 91.2 \\
\hline VaR at 5\% & 14.7 \\
\hline
\end{tabular}

After analyzing the VAR of the WTI from the historical series from 1991 to 2012, we observe that with a $95 \%$ probability, the asset price will not fall by more than $13.89 \%$ of its value during a month.

\subsubsection{Since Structural Change}

Now, if we analyze the prices since the structural change occurred, we have $\mu=1 \%, \sigma=9 \%$ and p1t $-1=105$.

After making these calculations, we simulate 10,000 random numbers with normal distribution $(0 ; 1)$, (we will call those simulations $\eta)$, we can then obtain 10,000 random simulations of $\varepsilon(\varepsilon=$ $\left.\sigma^{*} \eta\right)$.

We calculate p1t because $\mu, \varepsilon, \log (\mathrm{p} 1 \mathrm{t}-1): \mathrm{p} 1 \mathrm{t}=(\mu+\varepsilon+\log (\mathrm{p} 1 \mathrm{t}-1))$; after P1t is $\operatorname{EXP}(\mathrm{p} 1 \mathrm{t})$, which is the possible value with 10,000 random numbers for our portfolio. We must order these numbers from lowest to highest.

Sorted once, we find that the mean value is 106.6 ; the value at $5 \%$ is 90.8 . Finally, the VAR at $5 \%$ is the difference between the mean value and the value at $5 \%(106.6-90.8=15.8)$.

\begin{tabular}{|l|l|}
\hline$\mu$ & $1 \%$ \\
\hline$\sigma$ & $9 \%$ \\
\hline $\mathrm{p} 1 \mathrm{t}-1$ & 105 \\
\hline
\end{tabular}

\begin{tabular}{|l|l|}
\hline Mean value & 106.6 \\
\hline Value at $5 \%$ & 90.8 \\
\hline VaR at $5 \%$ & 15.8 \\
\hline
\end{tabular}

\section{$5.1 .31991-2002$}

In this period, we have the following:

\begin{tabular}{|l|l|}
\hline$\mu$ & $0.16 \%$ \\
\hline$\sigma$ & $8.33 \%$ \\
\hline$p 1 t-1$ & 27.02 \\
\hline
\end{tabular}

\begin{tabular}{|l|l|}
\hline Mean value & 27.2 \\
\hline Value at $5 \%$ & 23.6 \\
\hline VaR at $5 \%$ & 3.55 \\
\hline
\end{tabular}

Analyzing the VAR with the series after the structural change in 2002 and with the series from 1991 to 2002, the value of the asset does not fall more than $14.80 \%$ and $13.89 \%$, for each period, respectively, with the probability of $95 \%$ during a one week period. 


\subsection{Value at Risk: $C v x$}

Next, we analyze the oil company Chevron (CVX). With the same process, we reach the following conclusion:

\subsubsection{Complete Series}

If we analyze all of the prices for all of the years, we find that the $\mu=0.70 \%, \sigma=5.69 \%$ and p1t-1=106.56.

The process is then the same as before for the remainder of the examples, so we refer to the results:

The mean value is 107.5 ; the value at $5 \%$ is 97.5 . Finally, the VAR at $5 \%$ is the difference between the mean value and the value at $5 \%(107.5-97.7=9.7)$.

\begin{tabular}{|l|l|}
\hline$\mu$ & $0.7 \%$ \\
\hline$\sigma$ & $5.69 \%$ \\
\hline $\mathrm{p} 1 \mathrm{t}-1$ & 106.56 \\
\hline
\end{tabular}

\begin{tabular}{|l|l|}
\hline Mean value & 107.5 \\
\hline Value at 5\% & 97.5 \\
\hline VaR at 5\% & 9.7 \\
\hline
\end{tabular}

After analyzing the VAR results from a monthly historical series from 1991 to 2012, we can conclude that the CVX value will fall under $\$ 97.5$ in one month with just a 5\% probability. This measure can help an investor to analyze the risk that he is willing to take; he can be sure that with a probability of $95 \%$, his asset will not fall more than $\$ 9.7(9.02 \%)$ of its value.

\subsubsection{Structural Change}

\begin{tabular}{|l|l|}
\hline$\mu$ & $0.67 \%$ \\
\hline$\sigma$ & $5.91 \%$ \\
\hline $\mathrm{p} 1 \mathrm{t}-1$ & 106.56 \\
\hline
\end{tabular}

\begin{tabular}{|l|l|}
\hline Mean value & 107.5 \\
\hline Value at 5\% & 97.3 \\
\hline VaR at $5 \%$ & 10.1 \\
\hline
\end{tabular}

5.2.3 1991-2002

\begin{tabular}{|l|l|}
\hline$\mu$ & $0.67 \%$ \\
\hline$\sigma$ & $5.91 \%$ \\
\hline p1t-1 & 106.56 \\
\hline
\end{tabular}

\begin{tabular}{|l|l|}
\hline Mean value & 44.3 \\
\hline Value at 5\% & 40.4 \\
\hline VaR at 5\% & 3.9 \\
\hline
\end{tabular}

The results that we obtain analyzing the VAR with the series after the structural change in 2002 and with the series from 1991 to 2002 demonstrate that the value of the asset will not fall more than $\$ 10.1$ and $\$ 3.9$, respectively $(9.39 \%$ and $8.80 \%$ of its value, respectively), with a probability of $95 \%$.

This result shows us that before the structural change, the risk is much less than after the change, which demonstrates that the change first occurred in the commodity market and then in the oil companies.

We express the results from the remaining sample in the Appendix 1.

\section{Conclusion: What Are the Implications for Investors?}

When creating a portfolio, it is very important for investors to take into account certain 
statistical properties of the assets such as variance, mean and VAR. Many portfolio and/or asset valuations have proven to be wrong because of a poor choice of statistical values. For example, it is important to know what periods we will choose to obtain our statistics; a bad choice could lead us to poor statistics.

However, first of all, we should know the optimal time period for the data. The data series might not be totally relevant if it contains a structural break, and some statistics could be affected or could simply be wrong. These data can be obtained thanks to the Chow test, which determines if a series of data are affected by a structural change; moreover, we can estimate when the structural change occurred.

As many researchers know, the prices of the oil were affected by a structural change, which we analyzed. First, we obtained the result of the Chow test (identifying the date of the structural break). We then observed that important data such as the variance or the VAR vary significantly depending on the period that is chosen to calculate these values, which has significant implications in the financial world.

If an investor wants to create a portfolio, choosing an inadequate variance or VAR could lead to erroneous results. If an investor creates a portfolio composed of particular assets and assumes a volatility of $20 \%$, whereas the volatility was actually $30 \%$, the actual results could vary materially from those expected. In this study, we observed that the variance is generally higher after the structural change in both oil and oil company prices.

Concerning the VAR, if we invest a certain amount of money in oil and chose the historical data series from 1995, we could lose more than we expected. Continuing this study, we also found that the oil VAR and the VAR of most oil companies is greater after the structural change; if an investor assumes a loss of $12 \%$ and loses $17 \%$, it could influence the portfolio is managed.

STD. Deviation Total Period < STD. Deviation Period: 2002-2007

VAR $_{\text {Total Period }}<$ VAR Period: 2001-2007

After analyzing the VAR of these assets, we can conclude that the value will fall by a higher amount in the WTI than in the oil company because we observed that the difference in the fall of the price from one to the other is approximately $2 \%$. We believe that this fact can be related to the diversification of the share prices of the oil companies.

\section{Acknowledgements}

This paper is the sole responsibility of its authors, and the views represented here do not necessarily reflect those of the Banco de España. We thank Luis Diaz Marcos, Juan José Tenorio Blázquez and Juan Diaz Andreo for their useful suggestions. We also acknowledge the financial support of Junta de Castilla-La Mancha grant PEII11-0031-6939 (Javier Población) and of the Ministerio de Educación grant ECO2011-28134 (Javier Población).

\section{References}

Bruce Morley, Chow Test for Structural Stability, University of Bath. Available: http://www.people.bath.ac.uk/bm232/.../Chow\%20Test.doc 


\section{Macrothink}

Business and Economic Research ISSN 2162-4860 2013, Vol. 3, No. 1

Brennan, M. J. \& Schwartz, E. S. (1985), Evaluating natural resource investments, Journal of Business, 58, 133-155. http://dx.doi.org/10.1086/296288

Cortazar, G. \& Schwartz, E. S. (2003), Implementing a stochastic model for oil futures prices, Energy Economics, 25, 215-218. http://dx.doi.org/10.1016/S0140-9883(02)00096-8

Cortazar G. \& Naranjo L. (2006). An N-Factor gaussian model of oil futures prices, The Journal of Futures Markets, 26, 209-313. http://dx.doi.org/10.1002/fut.20198

Federal Trade Commission, (2004). The Petroleum Industry, http://www.ftc.gov/os/2004/08/040813mergersinpetrolberpt.pdf

Laugthton, D.G. \& Jacoby, H.D. (1993), "Reversion, timing options, and long-term decision making”, Financial Management, 33, (pp. 225-240). http://dx.doi.org/10.2307/3665940

Laugthton, D. G. \& Jacoby, H. D. (1995), The effects of reversion on commodity projects of different length (pp. 185-205), in L. Trigeorgis, (Ed.), Real Options in Capital Investment: Models, Strategies and Applications, Praeger, Westport, CT.

Ron Alquist \& Lutz Kilian \& Robert Vigfusson (2011), "Forecasting the Price of Oil" Investopedia US (2010), An Introduction To Value at Risk (VAR), Investopedia. http://www.investopedia.com/articles/04/092904.asp\#axzz2E0s1NbSG

Ross, S. A. (1997), Hedging long run commitments: Exercises in incomplete market pricing, Banca Monte Econom. Notes, 26, 99-132.

Schwartz, E. S. (1997), The stochastic behavior of commodity prices: Implication for valuation and hedging, The Journal of Finance, 52, pp. 923-973. http://dx.doi.org/10.1111/j.1540-6261.1997.tb02721.x

Schwartz, E. S. \& Smith, J. E. (2000), Short-term variations and long-term dynamics in commodity prices, Management $\quad$ Science, $\quad 46, \quad 893-911$. http://dx.doi.org/10.1287/mnsc.46.7.893.12034

Seth, A. K. (2007). Granger causality, Scholarpedia. http://www.scholarpedia.org/article/Granger_causality

\section{Appendix 1.}

Shell:

Table 5.BP:

Table 6.Brent

Table 7.Diesel

Table 8.Asphalt 
Table 9.Repsol

Table 10.ENI

Table 11.

Table 5.

1. Complete series

\begin{tabular}{|l|l|}
\hline$\mu$ & $0.22 \%$ \\
\hline$\sigma$ & $7.81 \%$ \\
\hline $\mathrm{p} 1 \mathrm{t}-1$ & 3.3971 \\
\hline
\end{tabular}

\begin{tabular}{|l|l|}
\hline Mean value & 3.4 \\
\hline Value at 5\% & 3.0 \\
\hline VaR at 5\% & 0.420 \\
\hline
\end{tabular}

2. Structural change

\begin{tabular}{|l|l|}
\hline$\mu$ & $1.01 \%$ \\
\hline$\sigma$ & $6.03 \%$ \\
\hline$p 1 t-1$ & 3.3484 \\
\hline
\end{tabular}

\begin{tabular}{|l|l|}
\hline Mean value & 3.4 \\
\hline Value at 5\% & 3.1 \\
\hline VaR at 5\% & 0.3252 \\
\hline
\end{tabular}

3. 1991-2002

\begin{tabular}{|l|l|}
\hline$\mu$ & $0.53 \%$ \\
\hline$\sigma$ & $9.23 \%$ \\
\hline$p 1 t-1$ & 0.9840 \\
\hline
\end{tabular}

\begin{tabular}{|l|l|}
\hline Mean value & 1.0 \\
\hline Value at 5\% & 0.8 \\
\hline VaR at 5\% & 0.1419 \\
\hline
\end{tabular}

Table 6.

1. Complete series

\begin{tabular}{|l|l|}
\hline$\mu$ & $0.35 \%$ \\
\hline$\sigma$ & $7.38 \%$ \\
\hline p1t-1 & 7.2241 \\
\hline
\end{tabular}

\begin{tabular}{|l|l|}
\hline Mean value & 7.3 \\
\hline Value at $5 \%$ & 6.4 \\
\hline VaR at $5 \%$ & 0.8 \\
\hline
\end{tabular}

2. Structural change

\begin{tabular}{|l|l|}
\hline$\mu$ & $-0.10 \%$ \\
\hline$\sigma$ & $7.91 \%$ \\
\hline p1t-1 & 7.2241 \\
\hline
\end{tabular}

\begin{tabular}{|l|l|}
\hline Mean value & 7.2 \\
\hline Value at $5 \%$ & 6.3 \\
\hline VaR at $5 \%$ & 0.9 \\
\hline
\end{tabular}

1991-2002

\begin{tabular}{|l|l|}
\hline$\mu$ & $0.83 \%$ \\
\hline
\end{tabular}

\begin{tabular}{|l|l|}
\hline Mean value & 8.3 \\
\hline
\end{tabular}




\begin{tabular}{|l|l|}
\hline$\sigma$ & $6.76 \%$ \\
\hline p1t-1 & 8.258 \\
\hline
\end{tabular}

\begin{tabular}{|l|l|}
\hline Value at 5\% & 7.4 \\
\hline VaR at 5\% & 0.9 \\
\hline
\end{tabular}

Table 7.

1. Complete series

\begin{tabular}{|l|l|}
\hline$\mu$ & $0.70 \%$ \\
\hline$\sigma$ & $8.72 \%$ \\
\hline$p 1 t-1$ & 119.47 \\
\hline
\end{tabular}

\begin{tabular}{|l|l|}
\hline Mean value & 120.8 \\
\hline Value at $5 \%$ & 104.3 \\
\hline VaR at $5 \%$ & 16.5030 \\
\hline
\end{tabular}

2. Structural change

\begin{tabular}{|l|l|}
\hline$\mu$ & $1.31 \%$ \\
\hline$\sigma$ & $8.97 \%$ \\
\hline$p 1 t-1$ & 119.47 \\
\hline
\end{tabular}

\begin{tabular}{|l|l|}
\hline Mean value & 121.5 \\
\hline Value at 5\% & 104.4 \\
\hline VaR at 5\% & 17.1 \\
\hline
\end{tabular}

3. 1991-2002

\begin{tabular}{|l|l|}
\hline$\mu$ & $0.18 \%$ \\
\hline$\sigma$ & $8.57 \%$ \\
\hline p1t-1 & 25.58 \\
\hline
\end{tabular}

\begin{tabular}{|l|l|}
\hline Mean value & 25.7 \\
\hline Value at 5\% & 22.3 \\
\hline VaR at $5 \%$ & 3.5 \\
\hline
\end{tabular}

Table 8.

1. Complete series

\begin{tabular}{|l|l|}
\hline$\mu$ & $0.59 \%$ \\
\hline$\sigma$ & $9.73 \%$ \\
\hline$p 1 t-1$ & 3.1834 \\
\hline
\end{tabular}

\begin{tabular}{|l|l|}
\hline Mean value & 3.2 \\
\hline Value at $5 \%$ & 2.7 \\
\hline VaR at $5 \%$ & 0.4881 \\
\hline
\end{tabular}

2. Structural change

\begin{tabular}{|l|l|}
\hline$\mu$ & $1.20 \%$ \\
\hline$\sigma$ & $10.14 \%$ \\
\hline p1t-1 & 3.1834 \\
\hline
\end{tabular}

\begin{tabular}{|l|l|}
\hline Mean value & 0.8 \\
\hline Value at $5 \%$ & 0.7 \\
\hline VaR at $5 \%$ & 0.1 \\
\hline
\end{tabular}

3. 1991-2002

\begin{tabular}{|l|l|}
\hline$\mu$ & $0.08 \%$ \\
\hline$\sigma$ & $9.39 \%$ \\
\hline$p 1 t-1$ & 0.8018 \\
\hline
\end{tabular}

\begin{tabular}{|l|l|}
\hline Mean value & 0.8 \\
\hline Value at $5 \%$ & 0.7 \\
\hline VaR at $5 \%$ & 0.1 \\
\hline
\end{tabular}

Table 9. 
1. Complete series

\begin{tabular}{|l|l|}
\hline$\mu$ & $0.33 \%$ \\
\hline$\sigma$ & $7.42 \%$ \\
\hline $\mathrm{p} 1 \mathrm{t}-1$ & 237.5 \\
\hline
\end{tabular}

\begin{tabular}{|l|l|}
\hline Mean value & 238.9 \\
\hline Value at $5 \%$ & 210.9 \\
\hline VaR at $5 \%$ & 27.9967 \\
\hline
\end{tabular}

2. Structural change

\begin{tabular}{|l|l|}
\hline$\mu$ & $1.12 \%$ \\
\hline$\sigma$ & $6.91 \%$ \\
\hline$p 1 t-1$ & 237.5 \\
\hline
\end{tabular}

\begin{tabular}{|l|l|}
\hline Mean value & 240.7 \\
\hline Value at $5 \%$ & 214.4 \\
\hline VaR at $5 \%$ & 26.4 \\
\hline
\end{tabular}

3. 1991-2002

\begin{tabular}{|l|l|}
\hline$\mu$ & $0.07 \%$ \\
\hline$\sigma$ & $7.59 \%$ \\
\hline$p 1 t-1$ & 145 \\
\hline
\end{tabular}

\begin{tabular}{|l|l|}
\hline Mean value & 145.9 \\
\hline Value at 5\% & 128.8 \\
\hline VaR at 5\% & 17.1 \\
\hline
\end{tabular}

Table 10.

1. Complete series

\begin{tabular}{|l|l|}
\hline$\mu$ & $0.34 \%$ \\
\hline$\sigma$ & $7.78 \%$ \\
\hline$p 1 t-1$ & 19.12 \\
\hline
\end{tabular}

\begin{tabular}{|l|l|}
\hline Mean value & 19.2 \\
\hline Value at 5\% & 16.9 \\
\hline VaR at 5\% & 2.3598 \\
\hline
\end{tabular}

2. Structural change

\begin{tabular}{|l|l|}
\hline$\mu$ & $0.33 \%$ \\
\hline$\sigma$ & $8.76 \%$ \\
\hline p1t-1 & 19.12 \\
\hline
\end{tabular}

\begin{tabular}{|l|l|}
\hline Mean value & 19.3 \\
\hline Value at $5 \%$ & 16.6 \\
\hline VaR at $5 \%$ & 2.6 \\
\hline
\end{tabular}

3. 1991-2002

\begin{tabular}{|l|l|}
\hline$\mu$ & $0.35 \%$ \\
\hline$\sigma$ & $6.96 \%$ \\
\hline$p 1 t-1$ & 13.20 \\
\hline
\end{tabular}

\begin{tabular}{|l|l|}
\hline Mean value & 13.3 \\
\hline Value at 5\% & 11.8 \\
\hline VaR at 5\% & 1.5 \\
\hline
\end{tabular}

Table 11.

1. Complete series

\begin{tabular}{|c|c|}
\hline$\mu$ & $0.59 \%$ \\
\hline$\sigma$ & $7.08 \%$ \\
\hline
\end{tabular}

\begin{tabular}{|l|l|}
\hline Mean value & 22.4 \\
\hline Value at 5\% & 19.9 \\
\hline
\end{tabular}


p1t-1

22.19

2. Structural change

\begin{tabular}{|l|l|}
\hline$\mu$ & $0.31 \%$ \\
\hline$\sigma$ & $6.79 \%$ \\
\hline$p 1 t-1$ & 22.19 \\
\hline
\end{tabular}

3. 1991-2002

\begin{tabular}{|l|l|}
\hline$\mu$ & $1.04 \%$ \\
\hline$\Sigma$ & $7.52 \%$ \\
\hline $\mathrm{p} 1 \mathrm{t}-1$ & 15.36 \\
\hline
\end{tabular}

\begin{tabular}{|l|l|}
\hline Mean value & 22.3 \\
\hline Value at $5 \%$ & 19.9 \\
\hline VaR at $5 \%$ & 2.4 \\
\hline
\end{tabular}

\begin{tabular}{|l|l}
\hline VaR at $5 \%$ & 2.5044
\end{tabular}

\section{Copyright Disclaimer}

Copyright reserved by the author(s).

This article is an open-access article distributed under the terms and conditions of the Creative Commons Attribution license (http://creativecommons.org/licenses/by/3.0/). 